\title{
The efficacy of tenofovir-based therapy in patients showing suboptimal response to entecavir-adefovir combination therapy
}

\author{
Jeong Han Kim', Sung Hyun Ahn², Soon Young Ko', Won Hyeok Choe', Kyun-Hwan Kim², and So Young Kwon' \\ ${ }^{1}$ Department of Internal Medicine, Konkuk University School of Medicine, Seoul; ${ }^{2}$ Department of Pharmacology and Center for Cancer \\ Research and Diagnostic Medicine, IBST, Konkuk University School of Medicine, Seoul, Korea
}

Background/Aims: Before tenofovir (TDF) become available in South Korea, combination therapy with entecavir (ETV) and adefovir (ADV) was the most potent regimen for chronic hepatitis $B(C H B)$ patients who fail to respond to rescue therapy for drug resistance. We analyzed the efficacy of ETV-ADV combination therapy and investigated the clinical and clonal results of TDF-based rescue therapy in CHB patients refractory to this combination.

Methods: We retrospectively reviewed the medical records of CHB patients treated for up to 3 years with ETV-ADV combination therapy as a rescue therapy for drug resistance. In cases refractory to this combination, clinical and clonal analyses were performed for TDF-based rescue therapy.

Results: The analysis was performed on 48 patients. Twelve patients achieved a virological response (VR) within 3 years. A VR was subsequently achieved in nine of the ten patients without a VR who switched to TDF monotherapy. A VR was also achieved in six of the seven patients who switched to lamivudine-TDF combination therapy, and in two of the two patients who switched to ETV-TDF combination therapy. In an in vitro susceptibility test, viral replication was detected with TDF monotherapy but not with ETV-TDF combination therapy.

Conclusions: The efficacy of ETV-ADV combination therapy was insufficient in CHB patients who were refractory to rescue therapy. A more potent regimen such as ETV-TDF combination therapy may be considered in such refractory cases. (Clin Mol Hepatol 2016;22:241-249)

Keywords: Chronic Hepatitis B; Entecavir; Adefovir; Lamivudine; Tenofovir; Resistance

\section{INTRODUCTION}

Hepatitis B virus (HBV) infection is a leading cause of chronic hepatitis, liver cirrhosis and hepatocellular carcinoma (HCC).$^{1-3}$ HBV infection is also the one of the most common etiology of chronic liver disease in South Korea. ${ }^{4}$ Long-term antiviral therapy is needed in most patients; however, incomplete viral suppression and emergence of drug resistance have been a major concern. ${ }^{5}$ The development of antiviral resistance is one of the most important predictive factors of the success or failure of chronic hepatitis $\mathrm{B}$ (CHB) treatment. ${ }^{6}$

To prevent the development of drug resistance, the current

\footnotetext{
Abbreviations:

$A D V$, adefovir; $A L T$, alanine amino transferase; $B R$, biochemical response; $C H B$, chronic hepatitis B; CLV, clevudine; DMEM, Dulbecco's modified Eagle's medium; ETV, entecavir; HBeAg, hepatitis B envelope antigen; HBV, hepatitis B virus; HCC, hepatocellular carcinoma; HEPES, 4-(2-hydroxyethyl)-1-piperazineethanesulfonic acid; LMV, lamivudine; PCR, polymerase chain reaction; PEG, polyethylene glycol; RFMP, restriction fragment mass polymorphism; RT, reverse transcriptase; TDF, tenofovir; VR, virological response
}

\section{Corresponding author : Jeong Han Kim}

Department of Internal Medicine, Konkuk University School of Medicine, Konkuk University Medical Center, 120-1 Neungdong-ro, Hwayang-dong, Gwangjin-gu, Seoul 05030, Korea

Tel: +82-2-2030-7764, Fax: +82-2-2030-5029

E-mail:93haan@hanmail.net 
treatment guidelines suggest entecavir (ETV) or tenofovir (TDF) as first-line antiviral agent for CHB treatment. ${ }^{6-9}$ However, ETV and TDF have been made available in South Korea only since 2007 and 2011, respectively. Therefore, most patients who started treatment before this period received lamivudine (LMV) or clevudine (CLV) as first-line treatment and subsequently developed drug resistance..$^{10} \mathrm{LMV}$-adefovir (ADV) combination therapy is the current most commonly used strategy for drug resistance. However, some patients fail to achieve a virological response (VR) with this combination and require a more potent treatment. Before TDF became available in South Korea, the ETV-ADV combination therapy has been the most potent regimen for CHB patients who are unresponsive to rescue therapy for drug resistance. The ETV-ADV combination has been reportedly used as a rescue therapy for CHB patients with treatment failure. ${ }^{11-17}$ However, many of these patients failed to achieve VR. We aimed to analyze the efficacy of ETV-ADV combination therapy and to investigate the clinical and clonal results of TDF-based rescue therapy in CHB patients refractory to ETV-ADV combination therapy.

\section{PATIENTS AND METHODS}

\section{Patients}

We retrospectively reviewed the medical records of $\mathrm{CHB}$ patients treated with a combination therapy with ETV $1 \mathrm{mg}$ plus ADV $10 \mathrm{mg}$ as rescue therapy for drug resistance more than 6 months at Konkuk University Hospital in Seoul, South Korea. The ETV-ADV combination therapy was started between July 2008 and October 2011, and final follow-ups were conducted until December 2014. Only patients who did not respond to more than 2 years of prior rescue therapy other than the ETV-ADV combination therapy were enrolled. In case of hepatitis $C$ or human immunodeficiency virus co-infection, patients who were receiving immunosuppressant therapy such as chemotherapy were excluded.

Serial serum samples were collected from each patient at the time of initiation of the ETV-ADV combination treatment and every 6 months during treatment and stored frozen at $-80^{\circ} \mathrm{C}$. Written informed consent for the collection of serum samples was obtained from all of the patients. The study protocol was approved by the Institutional Review Board of Konkuk university hospital (KUH1010496) and was conducted in accordance with the ethical guidelines of the 1975 Declaration of Helsinki.

\section{Clinical and laboratory assessments}

Laboratory data including serum alanine amino transferase (ALT), albumin, bilirubin, creatinine, HBV DNA, hepatitis B envelope antigen (HBeAg), and anti-HBe were measured at baseline and every 3 months during treatment. Serum HBV DNA levels were assessed by using the COBAS Amplicor polymerase chain reaction (PCR) assay (lower detection limit, $20 \mathrm{IU} / \mathrm{mL}$; Roche Molecular Systems, Branchburg, NJ, USA). Before initiation of the ETVADV combination therapy, antiviral-resistant mutations were tested by using a restriction fragment mass polymorphism (RFMP; Genematrix, Youngjin, South Korea). ${ }^{18}$

VR was defined as an undetectable HBV DNA level $(<20$ IU/ $\mathrm{mL}$ ), and biochemical response (BR) was defined as a normalized ALT level. Nonresponse was defined as $<2 \log _{10} \mathrm{IU} / \mathrm{mL}$ decline in the HBV DNA level from baseline after 6 months of therapy.

\section{Production of the HBV replicons}

We selected four patients with nonresponse and with HBV DNA $>4 \log _{10} \mathrm{IU} / \mathrm{mL}$ at 1 year. Sera collected from the patients at 1 year of treatment were studied.

The gene encoding the HBV polymerase reverse transcriptase (RT) domain was analyzed in these patients. The HBV DNA was extracted from sera samples obtained from the four patients by using the QIAamp MinElute virus spin kit (Qiagen) according to the manufacturer's protocol. The RT domains of wild-type (WT) HBV and HBV mutants isolated from sera were amplified and converted into the replication-competent HBV 1.2 mer constructs. Eight to 10 clones were obtained from each case, and sequencing of the RT domain was performed. In these clones, we generated several patient-derived HBV 1.2 mer replicons by switching the RT gene from WT HBV 1.2 mer replicon as previously described.19,20

\section{Cell culture and transfection}

Huh7 human hepatoma cancer cells were maintained in Dulbecco's modified Eagle's medium (DMEM; Gibco, Grandlsland, NY, USA), with additional condition of 10\% fetal bovine serum (Gibco) and $1 \%$ penicillin-streptomycin (Gibco), and incubated at $37^{\circ} \mathrm{C}$ in a $5 \% \mathrm{CO}_{2}$ environment. The cells were seeded $3 \times 10^{5}$ in a six-well plate and transiently transfected with $2 \mu \mathrm{g}$ of the HBV 1.2mer replicons by using Lipofectamine 2000 (Invitrogen, Carlsbad, CA, USA). 
Table 1. Baseline characteristics

\begin{tabular}{|c|c|c|c|c|}
\hline Variables & $\begin{array}{c}\text { Total } \\
(n=48)\end{array}$ & $\begin{array}{l}\text { Virological response } \\
\text { within } 3 \text { years }(+) \\
(n=12)\end{array}$ & $\begin{array}{l}\text { Virological response } \\
\text { within } 3 \text { years }(-) \\
(n=36)\end{array}$ & $P$-value \\
\hline Male (n, \%) & $41(85.4)$ & $11(91.7)$ & $30(83.3)$ & 0.662 \\
\hline Age (years)* & $48.0(29-71)$ & $52.5(30-65)$ & $48.0(29-71)$ & 0.384 \\
\hline Status (n, \%) & & & & 0.941 \\
\hline Chronic hepatitis & $33(68.8)$ & $8(66.7)$ & $25(69.4)$ & \\
\hline Cirrhosis & $12(25.0)$ & $3(25.0)$ & $9(25.0)$ & \\
\hline Hepatocelluar carcinoma & $3(6.3)$ & $1(8.3)$ & $2(5.6)$ & \\
\hline HBeAg positive (n, \%) & $47(97.9)$ & $11(91.7)$ & $36(100)$ & 0.250 \\
\hline HBV DNA $\left(\log _{10} 1 \mathrm{U} / \mathrm{mL}\right)^{*}$ & $5.8(4-10)$ & $5.6(4-8)$ & $6.0(4-10)$ & 0.323 \\
\hline $\operatorname{ALT}(I U / m L)^{*}$ & $39.0(13-216)$ & $50.0(26-77)$ & $32.5(13-216)$ & 0.140 \\
\hline Total bilirubin (IU/mL)* & $0.9(0.2-1.9)$ & $1.1(0.2-2.0)$ & $0.8(0.2-1.8)$ & 0.083 \\
\hline Albumin $(\mathrm{mg} / \mathrm{dL})^{*}$ & $4.4(3.6-4.9)$ & $4.5(3.9-4.9)$ & $4.4(3.6-4.8)$ & 0.084 \\
\hline Creatinine $(\mathrm{mg} / \mathrm{dL})^{*}$ & $1.0(0.6-1.3)$ & $0.9(0.6-1.2)$ & $1.0(0.6-1.3)$ & 0.552 \\
\hline Prothrombin time $(\mathrm{INR})^{*}$ & $1.0(1.0-1.3)$ & $1.2(1.0-1.3)$ & $1.0(1.0-1.3)$ & 0.867 \\
\hline Child-Pugh score* & $5.0(5.0-6.0)$ & $5.0(5.0-6.0)$ & $5.0(5.0-6.0)$ & 0.439 \\
\hline Initial treatment $(\mathrm{n}, \%)$ & & & & 0.199 \\
\hline LMV & $41(85.4)$ & $10(83.3)$ & $31(86.1)$ & \\
\hline CLV & $6(12.5)$ & $1(8.3)$ & $5(13.9)$ & \\
\hline ETV & $1(2.1)$ & $1(8.3)$ & 0 & \\
\hline \multicolumn{5}{|l|}{ Resistance mutation (n, \%) } \\
\hline LMV-R & $38(79.2)$ & $9(75.0)$ & 29 (80.6) & 0.695 \\
\hline L180M & 27 & 8 & 19 & \\
\hline M204I & 21 & 4 & 17 & \\
\hline M204V & 24 & 7 & 17 & \\
\hline$A D V-R$ & $10(20.8)$ & $2(16.7)$ & $8(22.2)$ & 1.000 \\
\hline A181S & 2 & 0 & 2 & \\
\hline A181T & 7 & 2 & 5 & \\
\hline A181V & 2 & 0 & 2 & \\
\hline N236T & 0 & 0 & 0 & \\
\hline ETV-R & $9(18.8)$ & $2(16.7)$ & $7(19.4)$ & 1.000 \\
\hline I169T & 2 & 0 & 2 & \\
\hline T184I & 2 & 0 & 2 & \\
\hline T184L & 5 & 1 & 4 & \\
\hline T184A & 1 & 0 & 1 & \\
\hline S202G & 3 & 2 & 1 & \\
\hline M250V & 1 & 0 & 1 & \\
\hline L180M+M204I & 7 & 2 & 5 & \\
\hline L180M+M204V & 10 & 3 & 7 & \\
\hline L180M+M204V+S202G & 1 & 1 & 0 & \\
\hline L180M+M204I+M204V & 7 & 2 & 5 & \\
\hline L180M+A181V+M204I & 1 & 0 & 1 & \\
\hline L180M+M204V+|169T+T184L & 1 & 0 & 1 & \\
\hline
\end{tabular}


Table 1. Continued

\begin{tabular}{|c|c|c|c|c|}
\hline Variables & $\begin{array}{c}\text { Total } \\
(n=48)\end{array}$ & $\begin{array}{c}\text { Virological response } \\
\text { within } 3 \text { years }(+) \\
(n=12)\end{array}$ & $\begin{array}{l}\text { Virological response } \\
\text { within } 3 \text { years }(-) \\
(n=36)\end{array}$ & $P$-value \\
\hline A181T & 5 & 2 & 3 & \\
\hline $\mathrm{A} 181 \mathrm{~T}+\mathrm{A} 181 \mathrm{~V}$ & 1 & 0 & 1 & \\
\hline M204I & 3 & 0 & 3 & \\
\hline M204I+A181T & 1 & 0 & 1 & \\
\hline M204I+A181S+|169T+T184| & 1 & 0 & 1 & \\
\hline $\mathrm{M} 204 \mathrm{I}+\mathrm{A} 181 \mathrm{~S}+\mathrm{T} 184 \mathrm{I}+\mathrm{T} 184 \mathrm{~A}$ & 1 & 0 & 1 & \\
\hline M204V+T184L & 2 & 0 & 2 & \\
\hline$M 204 V+M 250 V$ & 1 & 0 & 1 & \\
\hline $\mathrm{M} 204 \mathrm{~V}+\mathrm{T} 184 \mathrm{~L}+\mathrm{S} 202 \mathrm{G}$ & 2 & 1 & 1 & \\
\hline None & 4 & 1 & 3 & \\
\hline
\end{tabular}

LMV, lamivudine; ADV, adefovir; ETV, entecavir; CLV, clevudine; HBV, hepatitis B virus; HBeAg, hepatitis B envelope antigen; ALT, alanine aminotransferase.

"Median (range).

\section{Antiviral drugs and treatment condition}

ETV was purchased from Moravek (Brea, CA, USA), and ADV and TDF were obtained from Gilead Science (Foster City, CA, USA). After 4-6 $\mathrm{h}$ of post-transfection, the media were changed to fresh DMEM mixed with appropriate concentration of antiviral drugs. Each drug was treated every 4 days with daily change with fresh DMEM. The concentrations of the drugs were $20 \mu \mathrm{M}$ for TDF and $1 \mu \mathrm{M}$ for ETV.

\section{In vitro susceptibility and replication assay}

To analyze the HBV DNA replication capacity, Southern blot analysis was performed as described previously. ${ }^{19,20}$ We concisely summarize the procedure as follows: The transfected Huh7 cells were harvested at 4 days post-transfection for detection of HBV DNA intermediates. The cells were lysed with 4-(2-hydroxyethyl)1-piperazineethanesulfonic acid (HEPES) buffer (10 mM HEPES at pH 7.5, $100 \mathrm{mMNaCl}, 1 \mathrm{mM} \mathrm{EDTA}$, and 1\% NP-40). For elimination of transfected plasmid or cellular chromosomal DNA, the lysates were treated with DNasel (Clontech/Takara Bio, Mountain View, CA, USA) and mung bean nuclease (Clontech/Takara Bio) at $37^{\circ} \mathrm{C}$ for 15 minutes. Cytoplasmic core particles were precipitated with polyethylene glycol (PEG) solution (1.2 M NaCl, $60 \mathrm{mM}$ EDTA, 30\% sucrose, 26\% PEG 8000), and the capsid protein was digested with proteinase $\mathrm{K}(20 \mathrm{mg} / \mathrm{mL}$; Roche Applied Science, Indianapolis, IN, USA) in the presence of sodium dodecyl sulfate (SDS) at $37^{\circ} \mathrm{C}$ for 2 hours. To obtain purified HBV DNA, phenol extraction and ethanol precipitation was performed. The HBV
DNA was separated in $0.8 \%$ agarose gel. After transfer onto a Hybond-N+ membrane (GE Healthcare, Buckinghamshire, UK), HBV DNA was detected with a highly pure randomized HBV probe with labeled isotope.

\section{Statistical analyses}

Statistical testing was performed by using SPSS version 17.0 (SPSS Inc., Chicago, IL, USA). Data were expressed as median (range) and number (percentile). Continuous variables were compared by using the Mann-Whitney U-test. Categorical data were compared by using the chi-squared test or Fishcer exact test. A $p<0.05$ was considered statistically significant.

\section{RESULTS}

\section{Baseline Characteristics}

For the analysis, 48 patients were enrolled (Fig. 1). Of the patients, 41 (85.4\%) were male, and the median age was 48 years. Cirrhosis and HCC were detected in $12(25.0 \%)$ and 3 patients (6.3\%) respectively. All of the HCC patients were treated with radiofrequency ablation before ETV-ADV combination treatment. Most patients were HBeAg positive (47, 97.9\%), and the median HBV DNA level was $5.8 \log _{10} \mathrm{IU} / \mathrm{mL}$. The initial treatment agents were LMV in 41 patients (85.4\%), CLV in 6 patients (12.5\%), and ETV in 1 patient (2.1\%); (Table 1). 


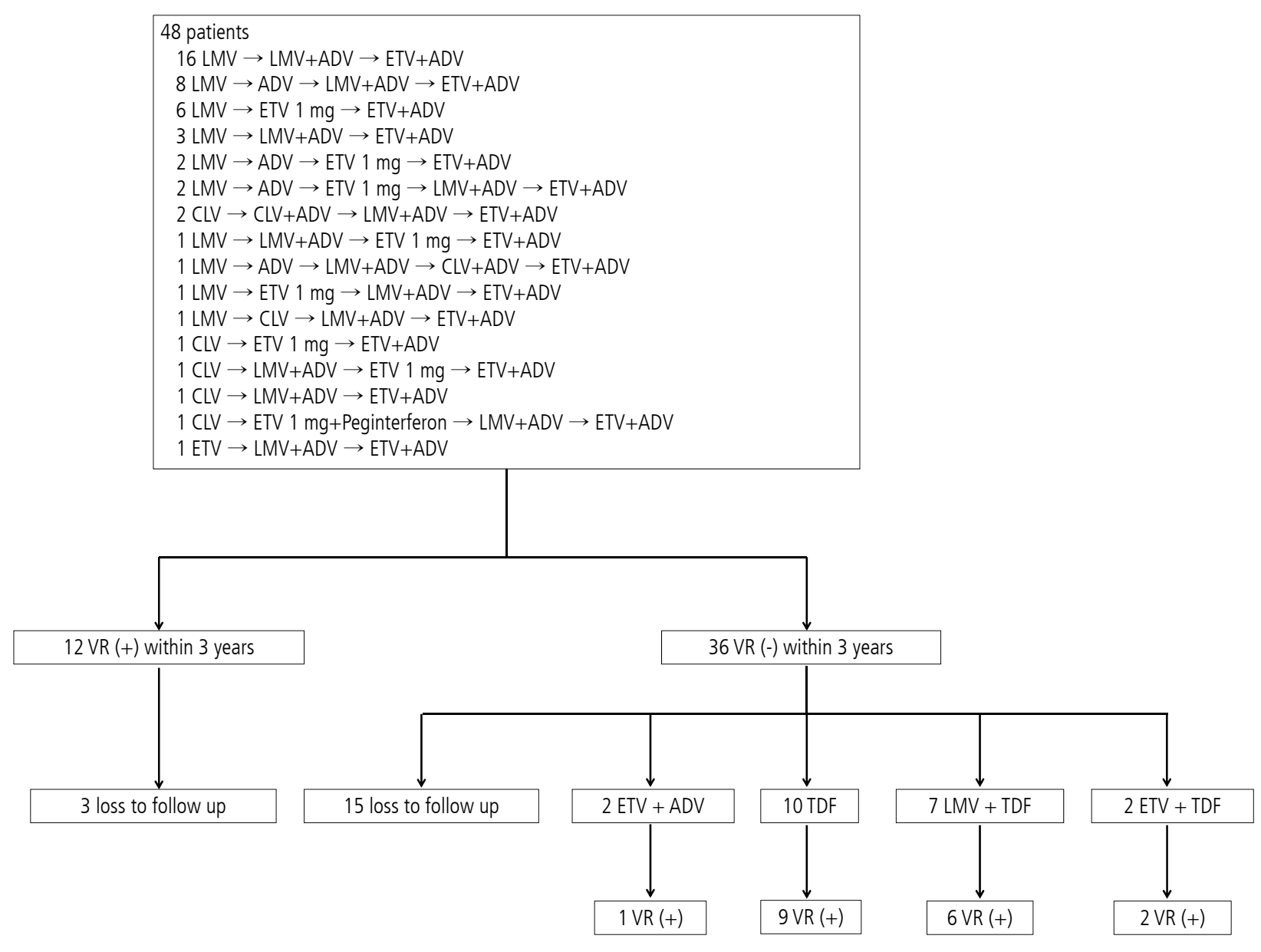

Figure 1. Flow chart of the enrolled patients.

\section{Treatment response to ETV-ADV combination therapy within 3 years}

Twelve patients achieved VR, and no difference in baseline characteristics were observed between the groups with or without VR (Table 1).

The VR rates were $6.5 \%(3 / 46)$ at month $6,18.6 \%(8 / 43)$ at month $12,26.7 \%(8 / 30)$ at month 24 and $52.9 \%(9 / 17)$ at month 36. The BR rates were $60.0 \%$ (27/45) at month $6,65.9 \%(29 / 44)$ at month $12,80.0 \%(24 / 30)$ at month 24 , and $100 \%(17 / 17)$ at month 36. Nonresponse was observed in 19 patients, $39.6 \%$ of all the patients and $52.8 \%$ of those without VR.

\section{Clinical courses of the patients without VR within 3 years}

Fifteen patients were lost to follow-up. Two patients continued the ETV-ADV combination regimen, and one patient achieved VR at month 42. Ten patients switched to TDF monotherapy (300 mg/ day), mutation test before switch showed no mutation in 4 , $\mathrm{L} 180 \mathrm{M}+\mathrm{M} 204 \mathrm{I}+\mathrm{M} 204 \mathrm{~V}$ in one, $\mathrm{L} 180 \mathrm{M}+\mathrm{M} 204 \mathrm{I}+\mathrm{M} 204 \mathrm{~V}+\mathrm{M} 250 \mathrm{~L}$ in one, $\mathrm{L} 180 \mathrm{M}+\mathrm{M} 204 \mathrm{~V}+\mathrm{M} 250 \mathrm{~V}$ in one, $\mathrm{L} 180 \mathrm{M}+\mathrm{M} 204 \mathrm{~V}+\mathrm{T} 184 \mathrm{~L}$ in two, M204I+A181S+T184I in one, and 9 of whom achieved VR within 1 year except the patients with L180M+M204V+M250V mutation. Seven patients switched to LMV (100 mg/day) plus TDF combination therapy, mutation test before switch showed no mutation in two, L180M+M204I in two, L180M+M204V in one, M204I in two, and 6 of whom achieved VR within 1 year except the patients with M204l. Two patients switched to ETV (1 mg/day) plus TDF combination therapy, mutations detected before switch were L180M+M204V+I169T+T184L, L180M+M204V+T184L+S202G, and all of whom achieved VR within 1 year (Fig. 1).

\section{Sequence evolution of HBV polymerase RT}

Four patients were selected for clonal evaluation (Table 2). Six 
Table 2. Demographic data of the selected patients

\begin{tabular}{|c|c|c|c|c|}
\hline & $\begin{array}{l}\text { Patient } 1 \\
\text { Clon } 100\end{array}$ & $\begin{array}{l}\text { Patient } 2 \\
\text { Clon } 105\end{array}$ & $\begin{array}{l}\text { Patient } 3 \\
\text { Clon } 108\end{array}$ & $\begin{array}{l}\text { Patient } 4 \\
\text { Clon } 109\end{array}$ \\
\hline Gender & Male & Female & Male & Male \\
\hline Age (years) & 47 & 51 & 30 & 38 \\
\hline $\mathrm{HBeAg}$ & + & + & + & + \\
\hline HBV DNA $\left(\log _{10} \mid \mathrm{U} / \mathrm{mL}\right)$ & 5.9 & 6.1 & 6.3 & 5.7 \\
\hline HBV DNA $\left(\log _{10} 1 \mathrm{U} / \mathrm{mL}\right)$ at serum collection time point & 4.3 & 4.8 & 5.3 & 4.6 \\
\hline $\mathrm{ALT}(\mathrm{IU} / \mathrm{mL})$ & 30 & 17 & 43 & 68 \\
\hline Total bilirubin (IU/mL) & 0.6 & 0.5 & 0.7 & 1.1 \\
\hline Albumin (mg/dL) & 4.4 & 4.2 & 4.2 & 4.7 \\
\hline Previous treatment & $\begin{array}{c}\text { LMV } \\
\text { LMV+ADV }\end{array}$ & $\begin{array}{c}\text { LMV } \\
\text { LMV+ADV }\end{array}$ & $\begin{array}{c}\text { LMV } \\
\text { LMV+ADV }\end{array}$ & $\begin{array}{c}\text { LMV } \\
\text { ADV } \\
\text { ETV } 1 \mathrm{mg}\end{array}$ \\
\hline \multicolumn{5}{|l|}{ Resistance mutation } \\
\hline & L180M & L180M & L180M & L180M \\
\hline & M204I/V & M204I/V & M204l/V & M204I \\
\hline Duration of ETV-ADV & 13 months & 16 months & 19 months & 13 months \\
\hline Rescue therapy with TDF & $\begin{array}{l}\text { TDF alone } \\
\text { VR (+) }\end{array}$ & $\begin{array}{l}\text { TDF alone } \\
\text { VR (+) }\end{array}$ & $\begin{array}{l}\text { TDF alone } \\
\text { VR (+) }\end{array}$ & Loss to follow up \\
\hline
\end{tabular}

LMV, lamivudine; ADV, adefovir; ETV, entecavir; TDF, tenofovir; HBV, hepatitis B virus; HBeAg, hepatitis B envelope antigen; ALT, alanine aminotransferase; VR, virological response.

clones were selected from the four patients and generated to 1.2 mer replicon by swapping the RT region of the WT 1.2 mer clone. The sequences were compared against the sequence from genotype C HBV (NCBI GenBank accession no. GQ872210). The sequence showed rtM204I/V with or without rtL180M mutation, and no ADV-, TDF-, nor ETV-resistant mutation (Fig. 2A).

\section{In vitro drug susceptibility test}

Next, we checked the replication capacity of these clones by Southern blotting. The YI/VDD mutation in the HBV RT region is well known to have a replication defect, and our cases also had replication-defective clones (Fig. 2B). ${ }^{21}$ To investigate the susceptibility to antiviral agents, TDF monotherapy and ETV-TDF combination treatment were initiated. Replication decreased after both treatments. However, replication was still detected after the long exposure in the case of TDF monotherapy despite the weak replication (Fig. 2C, D).

\section{DISCUSSION}

The last two decades have seen the introduction of oral antivi- ral agents for the treatment of HBV infection. ${ }^{3}$ Long-term antiviral therapy is needed in most patients, and incomplete viral suppression and emergence of drug resistance is a major concern. ${ }^{3}$ The development of antiviral resistance is one of the most important predictive factors of the success or failure of CHB treatment. ${ }^{6}$ Several practice guidelines suggest treatment strategies for $\mathrm{CHB}$ patients who are resistant to treatment. The main principle of these guidelines is to choose antiviral agents without cross-resistance and to begin rescue therapy as soon as possible. ${ }^{3}$

As previously mentioned, TDF became available in South Korea since 2011. Before TDF became available, the ETV-ADV combination therapy was the most effective treatment. There are several reports about ETV-ADV combination treatment for CHB patients with resistance. Cho et al. ${ }^{11}$ showed a significantly superior response to ADV plus ETV compared with LMV plus ADV in patients with CHB refractory to both LMV and ADV. Jeon et al. ${ }^{12}$ reported that the ETV-ADV combination therapy effectively reduced HBV DNA levels in patients with CHB who developed resistance to both LMV and ETV. Kim et al. ${ }^{13}$ showed that the ETV-ADV combination therapy is superior to the LMV-ADV combination therapy for ETV-refractory CHB patients. Yang et al. ${ }^{14}$ reported similar results and showed poorer response in patients with than in those 


\begin{tabular}{|c|c|c|c|c|c|c|c|c|c|c|c|c|c|c|c|c|c|c|c|c|c|c|c|c|c|c|c|c|c|c|}
\hline \multirow{2}{*}{ Number of clones } & \multicolumn{30}{|c|}{ Amino acid at RT position } \\
\hline & 11 & 13 & 15 & 55 & 80 & 84 & 110 & 124 & 126 & 163 & 180 & 183 & 204 & 208 & 214 & 220 & 224 & 226 & 229 & 238 & 259 & 261 & 263 & 266 & 267 & 269 & 272 & 277 & 317 & 333 \\
\hline GQ872210 & $E$ & $\mathrm{~N}$ & $R$ & $\mathrm{H}$ & $\mathrm{L}$ & $\mathrm{V}$ & $\mathrm{R}$ & $\mathrm{Y}$ & $\mathrm{H}$ & 1 & $\mathrm{~L}$ & $\mathrm{~F}$ & $M$ & V & $\mathrm{V}$ & $\mathrm{L}$ & 1 & $\mathrm{~N}$ & $\mathrm{~L}$ & $\mathrm{~N}$ & A & $\mathrm{P}$ & $E$ & $\mathrm{~V}$ & Q & $\mathrm{L}$ & $\mathrm{C}$ & $\mathrm{P}$ & $S$ & $\mathrm{~K}$ \\
\hline $100-7$ & & & & & 1 & & $\mathrm{~K}$ & & & & $M$ & & 1 & & & 1 & V & & & D & $T$ & $\mathrm{~L}$ & & & $\mathrm{~L}$ & I & $R$ & $\mathrm{~S}$ & & Q \\
\hline $105-1$ & & $\mathrm{H}$ & G & & 1 & & & $\mathrm{H}$ & Y & V & & $S$ & 1 & & & & & & & & $\mathrm{~T}$ & & D & I & & I & & & & \\
\hline $105-4$ & & $\mathrm{H}$ & G & & & & & $H$ & Y & & M & & v & & & & & $S$ & & & $\mathrm{~T}$ & & D & I & & I & & & & \\
\hline $108-1$ & G & & & $R$ & & $M$ & & & & & & & I & I & & I & V & & & & $\mathrm{T}$ & & & & L & 1 & & & & Q \\
\hline $108-5$ & & & & & & $M$ & & & & & $M$ & & I & & & I & V & & & $\mathrm{H}$ & $\mathrm{T}$ & & & & L & I & & & & $Q$ \\
\hline 109-1 & & & & & & & & & & & $M$ & & V & & A & & & & V & & $\mathrm{T}$ & & & & $\mathrm{L}$ & & & & A & Q \\
\hline
\end{tabular}

B
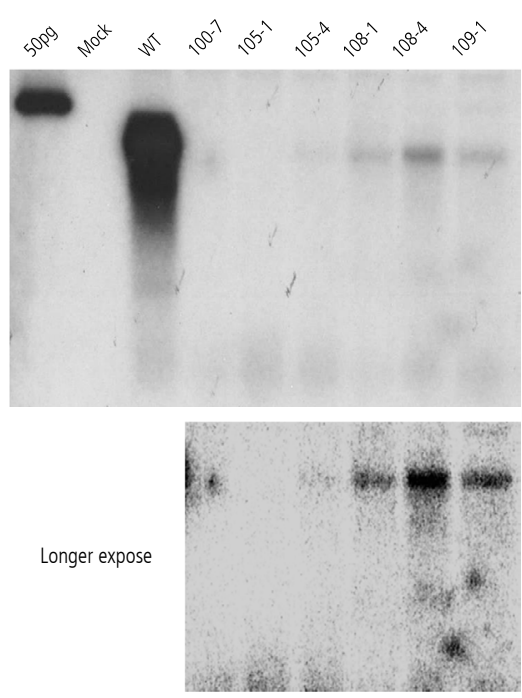

C

TDF


(D)

ETV+TDF

Figure 2. The in vitro sequence and drug susceptibility assay of the RT mutants isolated at 1-year treatment from the serum of CHB patients refractory to the ETV-ADV combination therapy. (A) The HBV RT genes from each serum sample were converted into HBV 1.2mer replicons, and the substitutions were compared with the wild type (NCBI GQ872210). (B-D) Cloned HBV DNAs were transfected into Huh7 cells, and the cells were treated for 4 days with $20 \mu \mathrm{M}$ TDF or $20 \mu \mathrm{M}$ TDF and $1 \mu \mathrm{M}$ ETV. The intracellular HBV DNA was analyzed by Southern blotting. The YI/VDD mutation in HBV RT region had a replication-defect.

without prior ADV resistance. Park et al. ${ }^{15}$ also reported a tendency toward better antiviral efficacy with ETV-ADV combination therapy than with LMV-ADV combination therapy and ETV monotherapy for multidrug-resistant CHB. Lim et al. ${ }^{16}$ showed that the ETV-ADV combination treatment was effective but its effect progressively decreased as the number of previously failed nucleoside/nucleotide analogues increased. Lim et al. ${ }^{17}$ also showed that the ETV-ADV combination therapy was effective for LMV-resistant CHB patients who showed suboptimal response to LMV plus ADV. These studies were limited by short follow-up periods. Our data shows result of up to 3 years. The VR rate to ETV-ADV combination was $52.9 \%$ within 3 years. This is unsatisfactory and a more potent strategy is warranted.

TDF has been well known to be effective as a rescue treatment for CHB patients with failure of prior treatment. ${ }^{22-24}$ Theoretically, the ETV-TDF combination therapy is the most powerful oral anti- viral treatment. Peterson et al. showed that rescue therapy with the ETV-TDF combination therapy in CHB patients harboring viral resistance patterns or showing only partial antiviral responses to preceding therapies was efficient, safe, and well tolerated. ${ }^{25}$ It was effective in both ADV- and ETV-resistant cases, but only the ETV-TDF combination regimen was studied. Meanwhile, comparative studies between ETV-TDF combination and TDF monotherapy in pretreated CHB patients are limited. Yip et al. ${ }^{26}$ reported that VR to ETV-TDF combination therapy and TDF monotherapy appeared to be similar in ETV partial responders. Choi et al. ${ }^{27}$ also reported that TDF monotherapy showed similar efficacy to that of TDF-nucleoside analogue combination therapy in patients with drug-resistant CHB. In the present study, the TDF-based rescue therapy was effective. Three among 4 patients selected for clonal evaluation were switched to TDF monotherapy and achieved VR clinically. The remaining patient was lost to follow-up. However, 
in vitro drug susceptibility tests in the present study showed incomplete viral suppression with TDF monotherapy and complete viral suppression with ETV-TDF combination therapy. It is already known that viral breakthrough and resistance can occur after VR, although other variants such as compliance must be considered.

Multidrug resistance is defined as resistance to two or more classes of antiviral drugs and combination of TDF and ETV $1 \mathrm{mg}$ is recommended for treatment. ${ }^{3,6-8}$ The RT sequence of these patients showed no ADV-, TDF- nor ETV-resistant mutation. Although no evidence of multidrug resistance has been found, such patients may need to be considered as similar to multidrug-resistant CHB patients. Although Korean guideline updated in year 2014 suggests both TDF monotherapy and TDF plus ETV combination therapy for multidrug resistant $\mathrm{CHB}$, treatment of multidrug resistance needs the combination of nucleoside and nucleotide analogues. ${ }^{3}$ ETV is the most potent nucleoside analogue, and TDF is the most effective nucleotide analogue. Furthermore, a recently published case report showed virological and biochemical breakthroughs during TDF treatment in a CHB patient who received sequential therapy. ${ }^{28}$ While TDF-based therapy is a promising approach and is currently the best option in the management of CHB patients with antiviral resistance, long-term follow-up data from well-designed trials will allow physicians to select the best therapeutic options for their patients with antiviral-resistant $\mathrm{CHB}^{29}{ }^{29}$ Response-guided therapy can be a good option. Further investigation about the decision of choice between TDF monotherapy and ETV-TDF combination therapy is warranted. Quantitation of hepatitis B surface antigen also can be a candidate indicator of treatment response in drug-resistant CHB patients. ${ }^{10}$

This study had several limitations. First, it is a small-scale retrospective analysis of ETV-ADV combination therapy. However, this study evaluated a longer period of treatment than those evaluated in previous studies. Second, the efficacy of TDF-based rescue therapy was investigated by conducting an in vitro study and short-term clinical observation. A large-scale prospective comparative study between TDF monotherapy and a combination of nucleoside analogues is warranted.

In conclusion, the efficacy of the ETV-ADV combination was insufficient for the CHB patients who were refractory to rescue therapy. For cases refractory to the ETV-ADV combination therapy, a more potent regimen such as the ETV-TDF combination therapy may be considered.

\section{Conflicts of Interest}

The authors have no conflicts to disclose.

\section{REFERENCES}

1. Ott JJ, Stevens GA, Groeger J, Wiersma ST. Global epidemiology of hepatitis B virus infection: new estimates of age-specific $\mathrm{HBsAg}$ seroprevalence and endemicity. Vaccine 2012;30:2212-2219.

2. Lai $\mathrm{CL}$, Yuen MF. Chronic hepatitis B--new goals, new treatment. $\mathrm{N}$ Engl J Med 2008;359:2488-2491.

3. Kim JH, Park YK, Park ES, Kim KH. Molecular diagnosis and treatment of drug-resistant hepatitis B virus. World J Gastroenterol 2014;20:5708-5720.

4. Lee SS, Byoun YS, Jeong SH, Kim YM, Gil H, Min BY, et al. Type and cause of liver disease in Korea: single-center experience, 2005 2010. Clin Mol Hepatol 2012;18:309-315.

5. Zoulim F, Locarnini S. Management of treatment failure in chronic hepatitis B. J Hepatol 2012;56(Suppl 1):S112-S122.

6. Korean Association for the Study of the Liver. KASL Clinical Practice Guidelines: Management of chronic hepatitis B. Clin Mol Hepatol 2012;18:109-162.

7. Liaw YF, Kao JH, Piratvisuth T, Chan HL, Chien RN, Liu CJ, et al. Asian-Pacific consensus statement on the management of chronic hepatitis B: a 2012 update. Hepatol Int 2012;6:531-561.

8. European Association For The Study Of The Liver. EASL clinical practice guidelines: Management of chronic hepatitis B virus infection. J Hepatol 2012;57:167-185.

9. Lok AS, McMahon BJ. Chronic hepatitis B: update 2009. Hepatology 2009;50:661-662.

10. Kim JH, Moon HW, Ko SY, Choe WH, Kwon SY. Hepatitis B surface antigen levels at 6 months after treatment can predict the efficacy of lamivudine-adefovir combination therapy in patients with lamivudine-resistant chronic hepatitis B. Clin Mol Hepatol 2014;20:274282.

11. Cho Y, Lee DH, Chung KH, Jin E, Lee JH, Cho EJ, et al. The efficacy of adefovir plus entecavir combination therapy in patients with chronic hepatitis B refractory to both lamivudine and adefovir. Dig Dis Sci 2013;58:1363-1370.

12. Jeon JW, Shin HP, Lee JI, Joo KR, Cha JM, Park JJ, et al. Efficacy of entecavir and adefovir combination therapy for patients with lamivudine- and entecavir-resistant chronic hepatitis B. Dig Dis Sci 2012;57:1358-1365.

13. Kim SS, Cheong JY, Lee D, Lee MH, Hong SP, Kim SO, et al. Adefovirbased combination therapy with entecavir or lamivudine for patients with entecavir-refractory chronic hepatitis B. J Med Virol 2012;84:18-25.

14. Yang HJ, Lee JH, Kim YJ, Yoon JH, Lee HS. Antiviral efficacy of combination therapy with entecavir and adefovir for entecavir/lamivu- 
dine-resistant hepatitis B virus with or without adefovir resistance. J Med Virol 2012;84:424-430.

15. Park MS, Kim BK, Kim KS, Kim JK, Kim SU, Park JY, et al. Antiviral efficacies of currently available rescue therapies for multidrugresistant chronic hepatitis B. Clin Mol Hepatol 2013;19:29-35.

16. Lim YS, Lee TH, Heo NY, Shim JH, Lee HC, Suh DJ. Entecavir plus adefovir combination treatment for chronic hepatitis B patients after failure of nucleoside/nucleotide analogues. Antivir Ther 2012;17:5360.

17. Lim YS, Lee JY, Lee D, Shim JH, Lee HC, Lee YS, et al. Randomized trial of entecavir plus adefovir in patients with lamivudine-resistant chronic hepatitis B who show suboptimal response to lamivudine plus adefovir. Antimicrob Agents Chemother 2012;56:2941-2947.

18. Yeon JE, Yoo W, Hong SP, Chang YJ, Yu SK, Kim JH, et al. Resistance to adefovir dipivoxil in lamivudine resistant chronic hepatitis B patients treated with adefovir dipivoxil. Gut 2006;55:1488-1495.

19. Ahn SH, Park YK, Park ES, Kim JH, Kim DH, Lim KH, et al. The impact of the hepatitis $B$ virus polymerase rtA181T mutation on replication and drug resistance is potentially affected by overlapping changes in surface gene. J Virol 2014;88:6805-6818.

20. Kwon SY, Park YK, Ahn SH, Cho ES, Choe WH, Lee CH, et al. Identification and characterization of clevudine-resistant mutants of hepatitis B virus isolated from chronic hepatitis B patients. J Virol 2010;84:4494-4503.

21. Melegari M, Scaglioni PP, Wands JR. Hepatitis B virus mutants associated with 3TC and famciclovir administration are replication defective. Hepatology 1998;27:628-633.

22. Lee $\mathrm{Cl}$, Kwon SY, Kim JH, Choe WH, Lee CH, Yoon EL, et al. Efficacy and safety of tenofovir-based rescue therapy for chronic hepatitis B patients with previous nucleo(s/t)ide treatment failure. Gut Liver 2014;8:64-69.

23. Kim HJ, Cho JY, Kim YJ, Gwak GY, Paik YH, Choi MS, et al. Longterm efficacy of tenofovir disoproxil fumarate therapy after multiple nucleos(t)ide analogue failure in chronic hepatitis B patients. Korean J Intern Med 2015;30:32-41.

24. Patterson SJ, George J, Strasser SI, Lee AU, Sievert W, Nicoll AJ, et al. Tenofovir disoproxil fumarate rescue therapy following failure of both lamivudine and adefovir dipivoxil in chronic hepatitis B. Gut 2011;60:247-254.

25. Petersen J, Ratziu V, Buti M, Janssen HL, Brown A, Lampertico P, et al. Entecavir plus tenofovir combination as rescue therapy in pretreated chronic hepatitis B patients: an international multicenter cohort study. J Hepatol 2012;56:520-526.

26. Yip B, Chaung K, Wong CR, Trinh HN, Nguyen HA, Ahmed A, et al. Tenofovir monotherapy and tenofovir plus entecavir combination as rescue therapy for entecavir partial responders. Dig Dis Sci 2012;57:3011-3016.

27. Choi K, Lee HM, Jun BG, Lee SH, Kim HS, Kim SG, et al. [Efficacy of Tenofovir-based Rescue Therapy for Patients with Drug-resistant Chronic Hepatitis B]. Korean J Gastroenterol 2015;65:35-42.

28. Lee HW, Chang HY, Yang SY, Kim HJ. Viral evolutionary changes during tenofovir treatment in a chronic hepatitis $\mathrm{B}$ patient with sequential nucleos(t)ide therapy. J Clin Virol 2014;60:313-316.

29. Kim JH, Lee JS. Is tenofovir disoproxil fumarate an all-powerful weapon in the treatment of chronic hepatitis B? Korean J Intern Med 2015;30:23-26. 